\title{
Income Redistribution Effect of Fiscal Transfer Payment —— Based on Analysis of Data from China's Provinces
}

\author{
Qu Ziqiao \\ School of Management. Wuhan University of Technology, Wuhan, China \\ quziqiao16@163.com
}

Keywords: transfer payment; income redistribution effect

\begin{abstract}
This paper studies the income redistribution effect of fiscal transfer payment in detail by analyzing the panel data of 31 provinces, municipalities and autonomous regions in China from 1999 to 2014. The results show that, in China, fiscal transfer expenditure reduces the per capita income of urban and rural areas, increases the income of urban and rural residents with a stronger effect on the increase of rural residents' income. As far as the region is concerned, the fiscal transfer expenditure has little effect on or slightly expand the income gap between urban and rural areas in the eastern region, while it has a light role in widening the income gap between urban and rural residents in the central region and has narrowed the income gap between urban and rural areas in the western region. In view of the above conclusions, this paper puts forward some countermeasures.
\end{abstract}

\section{Introduction}

In terms of the data released by the National Bureau of Statistics, China's Gini coefficient has been above the international cordon of 0.4 since 2003, even reaching 0.491 in 2008 . Although it has dropped in recent years, it remains above 0.46. In the 1980s, China's Gini coefficient only remained between 0.21 and 0.27 . Because the fairness of income distribution is a significant manifestation of social fairness, the larger income gap, the more various social contradictions will be stimulated, hindering the economic and social development of our country. Therefore, in recent years, China has adopted a series of income distribution reform measures to narrow the income gap, including adjusting the minimum wage. In addition to the above-mentioned related policies, our government has also established a financial transfer payment system to promote coordinated regional economic development thus alleviate the income gap. Through empirical research, this paper measures the adjustment effect of government financial transfer payment on residents' income gap from the national and regional levels, and puts forward countermeasures.

\section{Typical Facts}

\subsection{National Fiscal Transfer Expenditure}

Figure 1 shows the national fiscal transfer expenditure and its proportion data from 2002 to 2014. The blue curve represents the change of national fiscal transfer expenditure while the red curve represents the change of national fiscal transfer expenditure as a percentage of total fiscal transfer expenditure.

The two curves show that their trends are basically the same before 2008. However, the national transfer expenditure has been steadily increasing since 2008, but its percentage of total finance expenditure has not kept increasing, which indicates that the national total finance expenditure is also growing rapidly, so is the expenditure for other aspects, rather than simply increasing the fiscal transfer expenditure. 


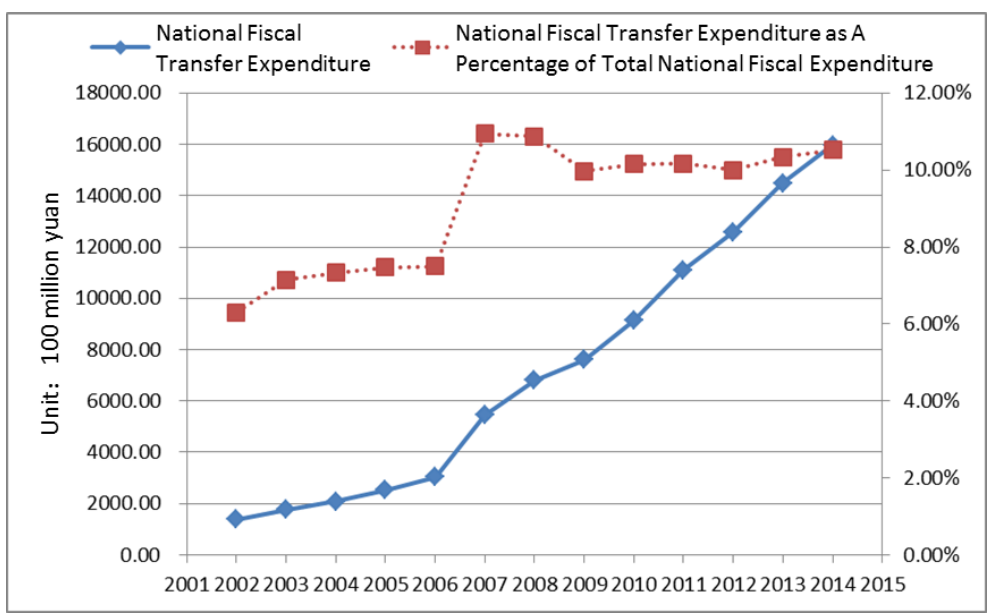

Figure 1 Trend of National Fiscal Transfer Expenditure and Its Proportion

\subsection{Central and Local Fiscal Transfer Expenditure}

Figure 2 shows the central and local fiscal transfer expenditure and its proportion. It can be seen that the central and local amount of money in transfer expenditure is increasing year by year, and the change curve in local transfer expenditure is almost exactly the same as that in national transfer expenditure, because local transfer expenditures are usually much larger than that in the central, so local transfer expenditure largely determines the national transfer expenditure. In addition, the central and local transfer expenditure amounts have increased by more than ten times in the past ten years, further demonstrating the importance that China pays attention to social security and livelihood issues, and the strength and determination to alleviate income inequality by means of financial transfer.

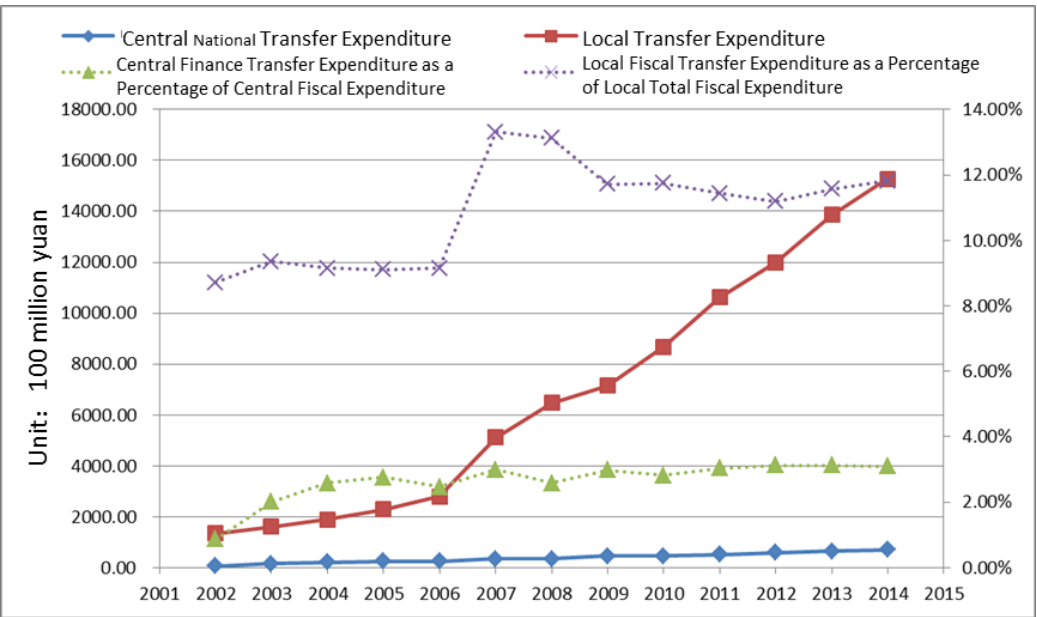

Figure 2 Trend of Central and Local Transfer Expenditure and their Proportion

In terms of comparison, it can be found that although the central and local transfer expenditure has maintained the growth trend, there are great differences in both the growth path and the change path of the proportion of expenditure. They have not developed simultaneously. The central and local transfer expenditures have been fluctuating instability in the process of the change of the proportion of expenditure, which is related to the unclear division of powers and responsibilities of expenditure in our country.

\subsection{Regional Fiscal Transfer Expenditure}

For comparison, we divide 31 provinces and cities in mainland China into China central, the eastern China and western region. China central has 8 provinces: Shanxi, Jilin, Heilongjiang, Anhui, Jiangxi, Henan, Hubei and Hunan. The eastern China includes 11 provinces and municipalities: Beijing, Tianjin, Hebei, Liaoning, Shanghai, Jiangsu, Zhejiang, Fujian, Shandong, Guangdong and Hainan and the western region includes 12 provinces and municipalities: Sichuan, 
Chongqing, Guizhou, Tibet, Yunnan, Shanxi, Guangxi, Gansu, Qinghai, Ningxia, Xinjiang and Inner Mongolia. Figure 3 shows the changes of fiscal transfer expenditure and its proportion in the central, eastern and western provinces from 1999 to 2014.

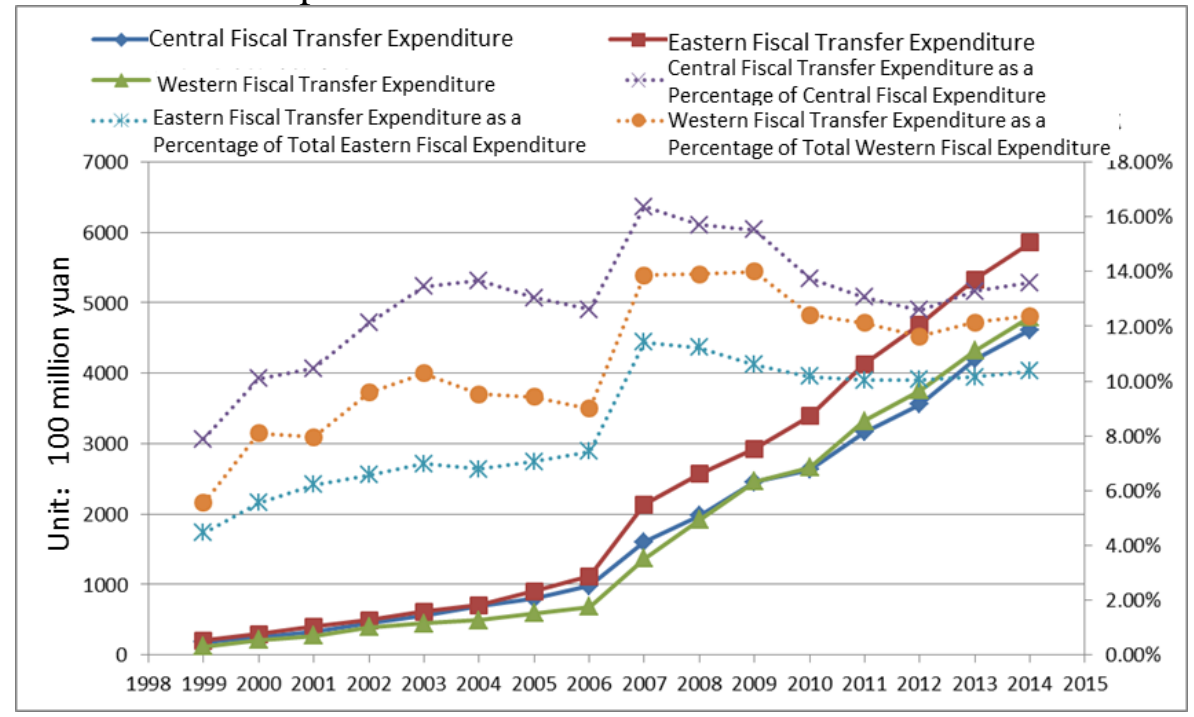

Figure 3Trend of Regional Transfer Expenditure and their Proportions

\section{Empirical Analysis}

Estimation method and variable selection

We adopt the basic model and the extended model. The basic model is:

$$
y_{i t}=\alpha_{0}+\beta_{1} \exp _{i t}+v_{i}+\varepsilon_{i t}
$$

In the formula, $i$ represents the province, $t$ represents the year ( 1999 - 2014 ), $\exp _{i t}$ represents the fiscal transfer expenditure, $v_{i}$ represents the individual effect of the province, $\varepsilon_{i t}$ represents the random interference term, and $\varepsilon_{i t}$ is an indicator to measure the income redistribution effect.

The core explanatory variable of this paper is fiscal transfer payment, which measured by financial transfer expenditure. The statistical caliber for 2006 and before is the sum of pension and social welfare relief expenses and social security subsidy expenses, and the statistical caliber after 2006 is social security and employment expenses.

The index of income redistribution effect is usually measured by Gini coefficient and income gap of residents. By consultation of the information and consideration of the availability of data, we select the ratio of urban per capita disposable income and rural per capita net income as this index. In the following discussion, we will carry out empirical analysis in China central, the eastern China and western region to observe and discuss the income gap between regions and between urban and rural areas in more detail.

In order to more accurately describe the impact of fiscal transfer expenditure on income redistribution, we add some control variables to the model to obtain the following extended model.

$$
y_{i t}=\alpha_{0}+\beta_{1} \exp _{i t}+\beta X_{i t}+v_{i}+\varepsilon_{i t}
$$

Among them, $X_{i t}$ is a control variable that affects income redistribution or income gap between urban and rural areas, mainly including the following indicators:

(1) Economic development: We use the annual GDP growth of each province to represent the economic development level of the province. Since the reform and opening up, China's economy has grown rapidly, but the income gap between residents has been widening. The urban economy is developing faster than that in the rural areas, the per capita income of urban residents is higher than 
that of rural residents, the southeast coast is developing faster than the inland, and the residents in the southeast coast are earning higher income than the inland residents. It is not difficult to find that the unbalanced economic development is an important factor which widens the income gap between urban and rural residents.

(2) Population: We use the total population of each province at the end of the year as the population index. Population factor has a direct impact on economic development and the income gap.

(3) Industrial structure: We use the proportion of the secondary industry in the overall industrial structure as the index of industrial structure. Since the foundation of the People's Republic of China, China's industrial structure has been adjusting and changing, with the focus gradually shifting from the agricultural economy to the industrial economy and then to the development of both industry and service industry. During this period, China's income gap has been continuously widening. Therefore, we believe that there is a correlation between the industrial structure and the income gap of residents. Since it accounts for the largest proportion of the national economy in most provinces and cities in China, and to some extent, the secondary industry is supported by China's cheap labor costs, that is, there is also an obvious income gap within the secondary industry, so we regard the proportion of the secondary industry as a control index.

(4) Fixed capital: We adopt the fixed asset investment amount of the whole society to represent fixed capital, which is the foundation of a region's long-term economic development and reflects the resource allocation to a certain extent. The income gap will be widened by the investment gap of fixed capital between regions and between urban and rural areas in the long run.

This paper adopts the data of 31 provinces, municipalities and autonomous regions in China from 1999 to 2014, which comes from China Statistical Yearbook from 2000 to 2015.

Analysis of Empirical Results

\section{National Total Sample Analysis}

In the basic regression, we regressed the urban per capita disposable income and the rural per capita net income as explanatory variables, so that we can not only see the impact of fiscal transfer expenditure on the urban-rural income ratio, namely, the income gap, but also summarize the impact of fiscal transfer expenditure on the income of urban and rural residents. For the per capita income of urban and rural residents, we have adopted the normalized value of logarithm. The regression results are shown in Table 1.

Table 1

\begin{tabular}{l|l|l|l|l|l|l}
\hline Variable & \multicolumn{2}{|l|}{$\begin{array}{l}\text { Income ratio between } \\
\text { urban and rural residents }\end{array}$} & $\begin{array}{l}\text { Urban per capita } \\
\text { income }\end{array}$ & \multicolumn{2}{l}{$\begin{array}{l}\text { Rural per capita } \\
\text { income }\end{array}$} \\
\hline constant term & $3.0218^{* * *}$ & $3.2459^{* * *}$ & $3.8779^{* * *}$ & $3.6713^{* * *}$ & $3.4065^{* * *}$ & $3.1293^{* * *}$ \\
\hline & $(29.54)$ & $(15.74)$ & $(203.00)$ & $(69.49)$ & $(118.93)$ & $(50.31)$ \\
\hline transferexpenditure & $-0.0002^{* * *}$ & $-0.0007^{* * *}$ & $0.0011^{* * *}$ & $0.0011^{* * *}$ & $0.0011^{* * *}$ & $0.0012^{* * *}$ \\
\hline & $(-3.13)$ & $(-3.59)$ & $(40.12)$ & $(16.68)$ & $(42.40)$ & $(17.56)$ \\
\hline economic growth & & $2.0931^{* * *}$ & & $0.5839^{* * *}$ & & $0.2487^{* * *}$ \\
\hline & & $(8.66)$ & & $(6.93)$ & & $(2.85)$ \\
\hline
\end{tabular}

$* * *, * *$ and $*$ represent the significance levels of $1 \%, 5 \%, 10 \%$, respectively.

In terms of the regression results of (1) (2), we can find that whether or not to adopt the control variable, the coefficient of transfer expenditure is significantly negative, indicating that the fiscal transfer expenditure has played a limited role in narrowing the urban-rural income gap from the small coefficient. The economic growth coefficient in the control variable is positive, indicating that the economic growth would widen the income gap, with the coefficient of 2.0931, that is, the urban-rural income ratio will enlarge 0.02 when the GDP increases by $1 \%$, so the economic growth would widen the income gap to a large extent.

The generalized moment estimation method does not need accurate distribution information of 
the random error term, allows the random error term to have heteroscedasticity and sequence correlation, and the obtained parameter estimation is more effective than other parameter estimation methods, so we use the system GMM method for model estimation.

$$
y_{i t}=\alpha_{0}+\beta_{1} \exp _{i t}+\beta X_{i t}+\phi y_{i t-1}+v_{i}+\varepsilon_{i t}
$$

The regression results are shown in Table 2:

Table 2

\begin{tabular}{l|l|l|l|l|l|l}
\hline Variable & Regression without control variables & \multicolumn{3}{l}{ Regression with control variables } \\
\hline & $\mathrm{Fe}$ & $\mathrm{Re}$ & $\mathrm{Gmm}$ & $\mathrm{Fe}$ & $\mathrm{Re}$ & $\mathrm{Gmm}$ \\
\hline lag term & & & $0.8855^{* * *}$ & & & $0.9204^{* * *}$ \\
\hline $\begin{array}{l}\text { constant } \\
\text { term }\end{array}$ & $3.0201^{* * *}$ & $3.0218^{* * *}$ & $(65.00)$ & & & $(62.34)$ \\
\hline & $(159.40)$ & $(29.54)$ & $(9.47)$ & $(8.99)$ & $(15.74)$ & $(5.13)$ \\
\hline $\begin{array}{l}\text { Transferex } \\
\text { penditure }\end{array}$ & $-0.0002^{* * *}$ & $-0.0002^{* * *}$ & $-0.0003^{* * *}$ & $-0.0008^{* * *}$ & $-0.0007 * * *$ & $-0.0002^{* * *}$ \\
\hline & $(-3.01)$ & $(-3.13)$ & $(-12.78)$ & $(-4.15)$ & $(-3.59)$ & $(-3.54)$ \\
\hline $\begin{array}{l}\text { economic } \\
\text { growth }\end{array}$ & & & & $2.0152^{* * *}$ & $2.0931^{* * *}$ & $-0.4988^{* * *}$ \\
\hline
\end{tabular}

$* * *, * *$ and $*$ represent the significance levels of $1 \%, 5 \%, 10 \%$, respectively.

Premised on table 2, we found that whether or not to adopt the control variable, the coefficient of lag term is significantly positive, which confirms our assertion that the previous period of the income gap does significantly affect the current income gap, and the lag term is close to 1 , indicating that the previous period of the income gap pattern is almost completely copied to the next period. These reflects the plight of low-income people in China, so it is difficult to achieve class leap and income span.

\section{Conclusion}

In national level, fiscal transfer expenditure reduces the per capita income of urban and rural areas, increases the income of urban and rural residents with a stronger effect on the rural residents, showing that China's fiscal transfer expenditure policy is effective, not only improving residents' lives, but also narrowing the gap between the rich and the poor, though the effect is limited.

As far as the region is concerned, the fiscal transfer expenditure has little effect on or slightly expand the income gap between urban and rural areas in the eastern region, while it has a light role in widening the income gap between urban and rural residents in the central region and has narrowed the income gap between urban and rural areas in the western region.

\section{References}

[1] James R. Brown, Bruce C. Petersen. Cash holdings and R\&D smoothing[J]. Journal of Corporate Finance,2010,17(3).

[2] Jiekun Huang, Darren J. Kisgen. Gender and corporate finance: Are male executives overconfident relative to female executives?[J]. Journal of Financial Economics,2013,108(3).

[3] Liu Y, Wei Z, Xie F. CFO gender and earnings management: evidence from China[J]. Review of Quantitative Finance \& Accounting, 2016, 46(4):881-905.

[4] Tim Opler, Lee Pinkowitz, René Stulz, Rohan Williamson. The determinants and implications of corporate cash holdings[J]. Journal of Financial Economics,1999,52(1). 